\title{
A Schema Therapy Approach to Complex Dissociative Disorder in a Cross-Cultural Setting: A Single Case Study
}

\author{
Alberto Barbieri ${ }^{1}$, Federica Visco-Comandini ${ }^{1}$, Alessandra Trianni ${ }^{1}$, \\ and Angelo Maria Saliani ${ }^{2}$ \\ ${ }^{1}$ MEDU Psyché Center for Transcultural Mental Health, Rome, Italy \\ ${ }^{2}$ Scuola di Psicoterapia Cognitiva, Rome, Italy
}

\begin{abstract}
Author note
Alberto Barbieri: https://orcid.org/0000-0002-0733-0008

Federica Visco-Comandini: https://orcid.org/0000-0002-3487-2320

Alessandra Trianni: https://orcid.org/0000-0002-8992-4669

Angelo Maria Saliani: https://orcid.org/0000-0002-1013-6361

We have no conflict of interest to disclose.

We would like to express our gratitude to "Ali" for his consent to use his case for this study. Furthermore, we are grateful to Moez Chamki and Giulia De Lucia for their assistance
\end{abstract} in this study.

Correspondence concerning the article should be addressed to Alberto Barbieri, MEDU Psyché Center for Transcultural Mental Health, Via Trebbia 3, 00198 Rome, Italy. Email: alberto.barbieri@mediciperidirittiumani.org 
SCHEMA THERAPY FOR COMPLEX DISSOCIATIVE DISORDER

\begin{abstract}
Complex dissociative disorders (CDD) include dissociative identity disorder (DID) and the most common other specified dissociative disorder (OSDD, type 1). One of the strongest predictors of CDD is antecedent trauma, particularly early childhood trauma. Currently, consensus-based treatment guidelines for CDD are lacking. Schema Therapy (ST) is a psychotherapeutic approach that has been recently proposed as a treatment for CDD given its emphasis on the consequences of early childhood neglect and abuse, and the explanation within the therapeutic model of the patient's experience of drastic shifts between personality states. The present case study examined the process of individual ST, in a three phases-based approach, with a 38-year-old male Arabic-speaking refugee with OSDD, type 1 (i.e., chronic dissociative disorder with mixed symptoms), posttraumatic stress disorder (PTSD) and borderline personality disorder (BPD). The setting included two therapists (co-therapy) and an interpreter/cultural mediator. We assessed the patient's change by using self-report assessments of dissociative and PTSD symptoms, cognitive schemas over 2-year and 4months treatment periods and a 6-months follow-up. We also assessed the therapeutic alliance. Posttreatment and follow-up reliable change analyses showed significant improvements in dissociative and PTSD symptoms as well as in some cognitive schemas. The therapeutic alliance between the patient and the therapists grew in a progressive and balanced way. This case study shows that ST within a phase-oriented approach may be an effective treatment for CDD. Our study also suggests cross-cultural validity of ST and, particularly, of modes construct. More research based on large samples is needed to confirm these assumptions.
\end{abstract}

Keywords: schema therapy, complex dissociative disorders, co-therapy, case study, crosscultural psychotherapy 
SCHEMA THERAPY FOR COMPLEX DISSOCIATIVE DISORDER

According to the Diagnostic and Statistical Manual of Mental Disorders, fifth edition (DSM-5; American Psychiatric Association [APA], 2013), dissociative disorders (DD) are characterized by a disruption of the usually integrated functions of memory, identity, emotion, perception, body, representation, motor control, and behavior. Disruption of identity includes confusion about one's identity as well as experiencing discrete and discordant senses of self, referred to as "identities", "personality states" or "dissociated self-states".

Complex dissociative disorders (CDD) include dissociative identity disorder (DID) and the most common dissociative disorder not otherwise specified (DDNOS, type 1), now known in the DSM-5 as other specified dissociative disorder (OSDD, type 1). The latter includes the subjects whose identity alteration is less marked to fully meet the diagnostic criterion of DID or who have identity alteration without dissociative amnesia. Patients suffering from CDD show high levels of impairment, high treatment utilization, and high treatment costs (Myrick, Webermann, Langeland, Putnam \& Brand, 2017). Numerous authors have demonstrated that pathological dissociation, DD and possession phenomena occur at comparable rates in many different cultures or countries (for an overview, see Krüger, 2020). CDD in particular have been found in prevalence studies around the world using systematic assessments, including validated interviews (Sar, 2011). One of the strongest predictors of dissociation is antecedent trauma, particularly early childhood trauma, as well as difficulties with attachment and parental unavailability (Dalenberg et al., 2012; Putnam, Harris \& Putnam, 2013; Schore, 2009). The relationship between dissociation and many types of trauma is robust and has been validated across cultures in clinical and nonclinical samples by several studies (Dalenberg et al., 2012).

Emotion dysregulation is a core feature of $\mathrm{CDD}$, as it is for borderline personality disorder (BPD). Indeed, there are many similarities between BPD and CDD, and DD and BPD have often been reported to occur comorbidly (Ross, 2007; Sar, Akyuz, Kugu, Ozturk \& 
SCHEMA THERAPY FOR COMPLEX DISSOCIATIVE DISORDER

Ertem-Vehid, 2006; Zittel, Conklin \& Westen, 2005). Similarly to dissociative symptoms, trauma experts conceptualize borderline symptoms as being based in childhood traumatic events (e.g., sexual abuse and/or physical abuse) and attachment difficulties, which contribute to difficulties with affect regulation (Putnam, 2013; van der Hart, Nijenhuis \& Steele, 2006; Herman, 1997; Herman, Perry \& van der Kolk, 1989; Liotti, 1992). Posttraumatic disorders are also common co-morbidities of patients with CDD (Simeon \& Loewenstein, 2009; Brand et al., 2019). For example, in a prospective treatment study of DID and DDNOS patients, 89\% also had posttraumatic stress disorder (PTSD; Brand et al., 2009).

Whereas consensus-based treatment guidelines for CDD are lacking, trauma and dissociation experts generally advocate for a three phases-based approach to treatment. In the first phase, safety and symptom stabilization is established, in the second phase traumatic memories are confronted and processed, and in the third phase identity integration and rehabilitation is addressed (International Society for the Study of Trauma and Dissociation, 2011). Recently, some authors presented schema therapy (ST) as an alternative for phaseoriented trauma treatment models (in short 'POTT-models') for DID, considering POTT lengthy and with rather high reported dropout rates (Huntjens, Rijkeboer \& Arntz, 2019). ST (Young, Klosko, \& Weishaar, 2003; Young, 1994) is an integrative therapy for personality disorders that combines elements of cognitive, behavioral, psychodynamic, and humanistic/experiential forms of psychotherapy. ST targets chronic emotional and cognitive maladaptive patterns, called "early maladaptive schemas" (EMS), which originate in adverse childhood experiences and early temperament. EMS are repeating themes about oneself and one's relationships that affect emotional processing, influence interpersonal style, and guide behavior. The primary objective of ST is to ameliorate EMS, replacing maladaptive coping responses with adaptive ones, and modify the transient, state-related manifestations of EMS, called "schema modes" which we refer to here as "modes" (Young et al., 2003). 
SCHEMA THERAPY FOR COMPLEX DISSOCIATIVE DISORDER

ST seems a viable option for the treatment of CDD given its emphasis on the consequences of early childhood neglect and abuse, and the explanation within the therapeutic model of the patient's experience of drastic shifts between personality states. It has been proposed that the dissociation between different modes as described by Young et al. (2003) can be coherently conceptualized in the framework of the structural organization of the personality and regards the concept of désagrégation (i.e., dis-integration) of the personality as originally advocated by Janet in his dissociation theory (1907). In the ST perspective, a dysfunctional mode can be considered as one of the aspects of the self that has not completely integrated with others in a cohesive personality structure and thus operates in a dissociated manner (Johnston, Dorahy, Courtney, Bayles \& O' Kane, 2009). Therefore, the various identities of a patient with DID are regarded as extreme expressions of dysfunctional modes, differing from the modes of patients with personality disorders in how the patient experiences the mode, that is in the degree of experienced dissociation from the other modes (Johnston et al., 2009; Lobbestael, van Vreeswijk, \& Arntz, 2007; Young et al., 2003).

This study aims to contribute to the current literature by exploring the use of ST in the understanding and treatment of a patient with CDD in a cross-cultural setting. To the best of our knowledge there are no studies to date which investigated either the cross-cultural validity of ST or its efficacy in non-Western patients. We describe the 2-year and 4-months outpatient ST treatment and 6-months follow-up of a 38-year-old male Arabic-speaking refugee with CDD, PTSD and BPD. First, we will describe the treatment process. We will then present scores of the process measures ratings and the progress of the patient as repeatedly measured during treatment by the Dissociative Experiences Scale - II (DES-II; Carlson \& Putnam, 1993), a self-report measure of EMS, and the Posttraumatic Stress Disorder Checklist (PCL-5; Weathers, Litz, Keane, Palmieri, Marx \& Schnurr, 2013). The rationale for applying ST to this specific case was that this is an evidence-based therapy 
SCHEMA THERAPY FOR COMPLEX DISSOCIATIVE DISORDER

covering a wide array of consequences following adulthood and childhood trauma, including BPD (Farrell, Shaw, \& Webber, 2009; Giesen-Bloo et al., 2006) and PTSD (Cockram, Drummon \& Lee, 2010). We adopted a therapeutic approach based on a trans-diagnostic model, emphasizing common pathways of partly overlapping clinical syndromes such as CDD, PTSD and borderline phenomena (Huntjens, Rijkeboer \& Arntz, 2019, Şar, 2017).

\section{Method}

\section{Patient}

Alì (fictitious name) is a Yemeni 38-year-old painter and art teacher, married and childless. At the time of his first clinical interview, he was living in a reception center in Italy, waiting for the results of his asylum application. Alì reported that he had to flee his country due to persecution, while his wife remained in the country. In Yemen, the patient was a teacher at the Institute of Art in his city. As he used to portray naked men and women, he was threatened by some of the parents of his students who complained that his teaching methods were contrary to morality. Alì was detained for three days by the police following allegations of immoral behavior. During his detention, the patient was tortured and sexually abused by the police officers. After some years, he was attacked by another man on a motorcycle who shot him while he was driving his car.

As a child Alì was neglected and suffered from physical and psychological abuses by his mother who was totally dedicated to her daughter (Alì's stepsister), who suffered from psychosis. When Alì was 10 years old, his mother left the rest of the family to go abroad with her daughter where she remained for 13 years before returning. Alì reported that he was generally protected by his father, even though he was often violent with his children and also with him. The patient also suffered episodes of sexual abuse by other adults during his childhood. Alì was assessed using the Structured Clinical Interview for DSM-5 (SCID-5; 
SCHEMA THERAPY FOR COMPLEX DISSOCIATIVE DISORDER

First, Williams, Karg \& Spitzer, 2016a) and the SCID-5 for Personality Disorders (SCID-5PD; First, Williams, Karg \& Spitzer 2016b). The diagnosis of DD was verified with the Dissociative Disorders Interview Schedule (DDIS; Ross, 1989). The patient fulfilled DSM-5 criteria for OSDD, type 1 (i.e., chronic dissociative disorder with mixed symptoms), PTSD, BPD with narcissistic and histrionic traits.

\section{Setting and Psychotherapists}

The case study took place at the Psyché Clinical Center for Transcultural Mental Health run by the medical humanitarian NGO Medici per i Diritti Umani (MEDU) in Rome (Italy). Dr. A.B., the case manager, and Dr. F.V.C., both certified cognitive-behavioral therapists, conducted the psychotherapy. Psychotherapy was given once a week in 60-minute sessions. All the first 17-months sessions were held in Arabic with the translation of an interpreter/certified cultural mediator native in Arabic which from now on we will refer to as the "interpreter". In the last stage, the sessions were held half in Italian and half in Arabic. The therapy sessions occurred with the two therapists present at the same time (i.e., cotherapy) and the interpreter. The interpreter assisted with both the translation and the decodification of the cultural issues related to the experienced distress. Some therapy sessions were audiotaped and examined during supervision with a certified ST supervisor and a certified cognitive-behavioral therapy (CBT) trainer with extensive ST experience (A.M.S.) providing feedback. Usually, trauma-focused treatments for PTSD in patients who have experienced multiple and/or prolonged interpersonal traumatic events (i.e., complex trauma) are made at the at the Psyché Clinical Center by two therapists. Co-therapy aims to prevent vicarious traumatization (Sexton, 1999) and compassion fatigue (Figley, 1995) through both mutual support and a diluted emotional drain for therapists who are faced with complex trauma cases that may be difficult to deal with alone (Russel \& Russel, 1979). Both the therapists and the interpreter had a minimum of three years of experience in mental health 
SCHEMA THERAPY FOR COMPLEX DISSOCIATIVE DISORDER

work in cross-cultural settings.

\section{Measures}

The measures used in the study are displayed in Table 1 . We used the translated Arabic versions of the Young Schema Questionnaire Short Form (YSQ-SF; Khater, Gilany, El-Belsha \& Abdel-Moneim, 2011), the PTSD Checklist for DSM-5 (PCL-5; Ibrahim, Ertl, Catani, Ismail \& Neuer, 2018), the Dissociative Experiences Scale-II (DES-II; Al-Eithan, Al Juban \& Robert, 2013). For any conceptual uncertainty on the items and/or on the Arabic terminology, the patient was supported by an independent interpreter (i.e., an interpreter different from the one who was part of the treatment team). For the therapy adherence ratings, we used the English version of the Schema Therapy Rating Scale (STRS; Young \& Fosse, 2005).

Process measure ratings. To measure therapeutic alliance, we used the Helping Alliance Questionnaire (HAq-II; Luborsky et al., 1996). Since the Arabic version of this selfreport questionnaire was not available, the independent interpreter translated each item out loud. The patient listened to each item and all the responses in Arabic and he then noted down his response. The interpreters attended a theoretical and practical training course on the use of all the study measures.

\section{Procedure}

Informed consent. Alì participated in the case study after giving written informed consent. He understood and agreed that we could make use of the therapists' notes, psychotherapy process, and measures for the purpose of the single case study. Additional informed consent was obtained for the audiotaped therapy sessions and for the publication of the drawings and paintings he donated to the therapists.

Psychotherapy process. The ST treatment process was documented on the basis of the therapists' case notes and extensive discussions between them. 
SCHEMA THERAPY FOR COMPLEX DISSOCIATIVE DISORDER

\section{Results}

\section{Patient's Pretreatment Scores on the Measures}

Alì obtained a pretreatment DES-II total score of 63.0. The DES-Taxon score (an eight-item measure drawn from the DES-II that determines whether the individual score is related to pathological dissociation) was 70.0. Table 2 provides the pretreatment scores for the YSQ-SF, PCL-5 total and sub-scales scores and the DES-II total and sub-scales scores.

\section{Psychotherapy process}

Alì began psychotherapy six months after arriving in Italy and continued for two years and four months for a total of 85 sessions.

\section{First Phase of Psychotherapy (stabilization; first five months approximately)}

Initial assessment. The stabilization phase lasted from session one to 17. During the first assessment sessions, Alì introduced himself as a very anxious person manifesting an apprehensive attitude evident from mimicry, gestures and language. Alì referred to "the loss of memory, getting lost, the boredom, the emptiness" as his main problems. He complained of frequent memory problems, difficulty in concentration and orientation, and rumination. In his opinion, "the loss of memory" started gradually since he was a child. The patient reported several recent episodes of amnesia concerning daily life events, especially in stressful situations, as well as impairment of episodic autobiographical memory (e.g., "I do not remember my marriage"). Moreover, the patient said that he often experienced an alteration in his sense of self (e.g., "During the day and during conversations I lose myself") and episodes of depersonalization (e.g., "I gave myself such strong slaps! It was as if another person had been slapped"). Alì also reported other three main problems. First, conversion symptoms, (i.e., temporary blindness episodes lasting about three minutes with concomitant strong chest pains) and somatic symptoms including tingling, recurrent headaches and widespread pain, especially in the back, chest, legs and right side of his body. Second, he 
SCHEMA THERAPY FOR COMPLEX DISSOCIATIVE DISORDER

reported difficulties in interpersonal relationships. Alì was unable to establish or maintain significant bonds in the affective, social and work environment. In this regard, the patient reported having felt pervasive shame in social situations since his childhood as well as deep anger towards people who made him feel worthless. Third, he showed posttraumatic symptoms linked to the complex trauma experienced in adulthood, including intrusions, avoidances, arousal alterations. Alì declared to often think about suicide: "I hold back only because it is a sin for my Islamic religion".

After some months of therapy, Alì began to report frequent episodes in which internal dialogues between what he called "personalities" suddenly started in his mind. An example of how the patient described these internal dialogues is illustrated by the following: "A part of me says that I am a genius, another says that I am sick and that I am worthless. I have too many things inside, if I speak, I will explode. I am fighting, contradicting myself, I get so tired. Since a long time those who are inside me are enemies (ed., This last statement was accompanied by an emotional crisis with crying). These personalities of mine have been around for a long time. There is a conflict within me. There is a good person who loudly says: they believe in you! Then there is a deeper voice that says: they are humiliating you, they are exploiting you! Sometimes I enjoy watching these internal dialogues, sometimes they force me to confront myself as if I was in a meeting. I am like a father who has to hold off to my child personality, if I cannot hold off to that bad child, the child would say disgusting things. I have to prevail over him, I have to control him, but sometimes I listen to him ". Alì mentioned sometimes the "bad child" as "the Devil".

The therapeutic alliance and the role of ancillary techniques. The stabilization phase sessions were mainly focused on improving patient's affect regulation and forming the therapeutic alliance as well as on ensuring that Psyché Center was perceived by Alì as a safe place. The patient was trained to recognize the cognitive basis of his dysfunctional behavior 
SCHEMA THERAPY FOR COMPLEX DISSOCIATIVE DISORDER

and painful emotions, in particular through the execution of numerous exercises employing the $\mathrm{ABC}$ technique (i.e., a CBT technique to investigate antecedents, cognitions, emotions and behaviors, of an event in the patient's life). The patient's emotions and beliefs were also investigated through the descriptions of the artistic works produced by the patient and presented by him during the sessions. The therapists instructed the patient to use some simple strategies for managing the most debilitating emotions such as anger and shame (e.g., relaxation techniques, memos on emotion awareness, $\mathrm{ABC}$ exercises). The patient was trained in short daily grounding exercises to help him stay focused in the present reality.

Additionally, the therapists wrote a medical-psychological report recognizing the patient as a survivor of torture. This report was important for the asylum application approval and helped to strengthen the patient's trust in the therapists. As a result, at the end of the assessment phase, the therapeutic alliance was considerably strengthened (e.g., in session 12 Alì said: "At first I thought you were the secret service. Now I understand that you are serious"). The last sessions of the stabilization phase were focused on trauma and ST psychoeducation. The therapists trained the patient on the "language" of EMS and modes, and they worked in collaboration with him to develop a shared understanding of the patient's problems using these concepts.

\section{Second Phase of Psychotherapy (Elaboration of traumatic memories; 12 months approximately)}

Retrieving childhood traumatic material. This phase lasted from session 18 to session 59. In session 18 the lifeline exercise was performed. The lifeline exercise is a tool developed by the Narrative Exposure Therapy (NET; Schauer, Neuner \& Albert, 2011) as an effective first step towards discussing the traumatic material. The purpose of the lifeline is the reconstruction of subjectively significant life events in their chronological order. Notably, the patient showed a relative difficulty in retrieving specific events of his childhood as the 
SCHEMA THERAPY FOR COMPLEX DISSOCIATIVE DISORDER

lifeline appeared almost completely "empty" of positive or negative autobiographical events until his late adolescence.

The following sessions were dedicated to investigating Alì's childhood asking the patient to remember his relationship with both parents as well as events from his childhood biography. At this point of the therapy the patient started to say that he was subjected to frequent episodes of abuse and neglect by his mother: 'My mother didn't touch me, didn't educate me, didn't show me any affection. She gave all the love and attention to my stepsister suffering from psychosis. My mother threatened me and beat me very hard. I was very afraid of her reactions". On the other hand, Alì tended to depict his father in a positive way, although he was sometimes described by the patient as a violent person. Alì began to use writing and drawings as a homework to recall episodes of his childhood (e.g., sexual abuse episodes), bypassing the barrier of shame present in verbal communication. In subsequent sessions, the patient began to tell of a first sexual abuse that he suffered by an acquaintance of his father when he was nine (see Figure 1a; in the drawing the patient re-enacts the event). The patient reported a following episode of sexual abuse by an adult when he was 15 . Alì reported also consenting homosexual relationships during his adolescence, although he said he did not like these kind of relationships.

Case conceptualization according to ST. The case was conceptualized in terms of ST since the patient's "personalities" and their dissociative aspects could be framed in EMS and, subsequently, in poorly integrated modes. After some psychoeducation sessions on experiential techniques, Alì accepted to do imagery exercises which the therapists felt were essential for the change of EMS and to facilitate the integration of dissociated modes. Indeed, ST makes extensive use of experiential techniques, such as chair dialogues, guided imagery and imagery rescripting (IR; Young et al., 2003) in order to reprocess the patient's emotional distress originating from painful childhood experiences. In session 23, the therapists 
SCHEMA THERAPY FOR COMPLEX DISSOCIATIVE DISORDER

performed the imagery exercise of the safe place. In this exercise, the patient identified the Psyché Center room as his safe place. During session 24, a diagnostic imagery exercise was performed to identify specific relevant episodes of the past and present which could lead to the identification of the EMS. In the following session, the therapists examined with the patient his most relevant EMS (e.g., Abandonment, Defectiveness/Shame and Entitlement/Grandiosity) and coping strategies. Some sessions were focused on psychoeducation about coping modes (i.e., surrender, avoidant, overcompensator). The patient identified avoidance as his prevailing coping strategy. The patient was also trained to compile flash cards, that is, cards containing a small amount of information on EMS, as an aid to remember in daily life the most convincing arguments against EMS and the most adaptive behavioral strategies.

At this moment of the treatment, Alì donated to the therapists the painting named "Alì Child" (see Figure 1b) where the patient represented himself as a little child $(<$ three years old) clinging to the legs of the two therapists as if in search of care and protection from them. Then, the sessions were focused on talking about the modes of the Abandoned/Abused Child that Alì named "The Bud without Water" and the Detached Protector (i.e., avoidant coping mode that patient named "Alì the Solitary"). In session 35, the first IR was made on the episode of Alì rejected by his mother when he was eight years old. In this memory, Alì sought the comfort of his mother but she abruptly pushed him away telling him that he should not cry and that she did not have time for him. During this exercise, Alì was able to introduce the Healthy Adult (formerly called the Counsellor and now named "Alì Kebir" which means adult in Arabic). In the following sessions, experiential exercises focused on the different Alì modes that gradually emerged (i.e., the Angry Child, the Abandoned/Abused Child, the Punitive Parent, the Detached Protector and the Overcompensator) were performed. The patient brought two more paintings. The first one depicted Alì Abandoned Child (Figure 1c; 
SCHEMA THERAPY FOR COMPLEX DISSOCIATIVE DISORDER

Ali represented himself as a 9 years old sad child waiting outside the closed door of the Psyché Center during the summer break). The second painting depicted "Alì the Solitary" (Figure 1d) represented as an adult in his room, isolated from the rest of the world. The painting also depicted aspects of the Overcompensator mode ("Ali the Genius") showing a wall on which the patient painted the different ways he intended to commit suicide. In this case, suicide was seen by Alì as an extreme act to claim his own greatness against those who in Italy humiliated him by treating him badly.

After 10 months, the case conceptualization was complete. As Alì found the concept of modes easier to understand than EMS, the therapists shared with the patient a simplified version of the case conceptualization (see Figure 2) using only schema modes. Modes were grouped by their function, constantly focusing on the underlying needs. The middle of Figure 2 shows the child and the punitive parent modes. Alì defined the Punitive Parent as "The Tough Mother". The Abandoned/Abused Child often felt fear of abandonment and terror of abuse while at other times he rather felt shame, experiencing humiliation and unworthiness related to childhood experiences with his mother. The Angry Child was defined by Alì in the first sessions as "The Devil who says lousy things" and then as "The Volcano". At the bottom, the dysfunctional coping modes (i.e., the Detached Protector and the Overcompensator) are represented. At the top, a little rectangle shape represents the Healthy Adult at the beginning of ST. The therapists shared with the patient the therapeutic goal deriving from the modes conceptualization (i.e., a progressive integration of the dissociated modes towards a more cohesive sense of self) and the integration process of achieving it, that is, strengthening the Healthy Adult that in this way is able to protect the Abandoned/Abused Child, regulate the Angry Child, counter the Punitive Parent, and contain the dysfunctional coping modes.

IR of the childhood abuse episode. In session 54, an IR was focused on the sexual 


\section{SCHEMA THERAPY FOR COMPLEX DISSOCIATIVE DISORDER}

abuse that Alì suffered from an acquaintance of his father when he was nine years old.

During the exercise, Alì introduced the Angry Child who violently attacked the abuser with a series of punches against a pillow held by the interpreter. The Tough Mother then scolded the child. At this point, Alì was able to introduce the Healthy Adult (Alì Kebir) who partially consoled him. Afterwards, the therapist came into the room and fully consoled the Abused Child. The following is the central dialogue of the IR:

Dr.A.B.: What are you feeling at the moment Alì?

Alì: I am disgusted by this man. I am afraid, I am terrified. I am afraid he will kill me. I try to escape but he is strong and he's holding me tight. I feel his lousy breath, his beard, his genitals. (Abused Child)

Dr. A.B.: What do you want right now?

Alì: I want help! May an adult help me, but there is no one around in this basement. I am afraid to scream because he will kill me! (Abused Child)

Dr. A.B.: At this moment the adult Alì enters the scene; Alì Kebir, what do you see?

Alì: I see a man abusing a child. Ifeel great anger. Even today when I see a strange adult approaching a child I remain alert (Healthy Adult).

Dr. A.B.: What do you do and what do you say now?

Alì: I tell the child to run away and be safe at home (Healthy Adult). I do not tell that man anything, I cannot say anything. I beat him. I have so much anger that grows; I do not control it. I need to hit something around here for hours! (The interpreter took a pillow and the patient repeatedly hit the pillow with a flurry of raging fists) (Angry Child)

Dr. A.B.: Now what are you saying to that man?

Alì: I want to insult him! (Alì begins to sob). That man is now on the ground, I still want to beat him; I want to destroy him (Angry Child)

Dr. A.B.: Where is the child now? What do you do for the child? 


\section{SCHEMA THERAPY FOR COMPLEX DISSOCIATIVE DISORDER}

Ali: He went away... I go to the father of the child and tell him to take care of him because he is a beautiful child and must be protected (Healthy Adult)

Dr. A.B.: What else do you do?

Ali: I tell the child, "Why did you go with that man to the basement? Nobody will believe you! We do not behave like that; you have to pay attention!" (Punitive Parent)

Dr. A.B.: Do you want to say or do something else as an adult?

Alì: No

Dr. A.B.: How is Alì as a child now?

Alì: I feel safer, the fear is gone. But I feel lonely, I need an older brother, an adult who will not abandon me (Abandoned Child)

Dr. A.B.: Can you do this as an adult for Alì as a child?

Ali: Yes, I caress the baby; I tell him "Do not be ashamed to tell your father things, but I will not always be there to help you. You have to trust other people too" (Healthy Adult)

Dr. A.B.: How does Alì child feel now?

Alì: A little better; but could you help me not to feel alone too? (Abandoned Child)

Dr. A.B.: Okay, I will enter the scene and I am close to you along with Alì Kebir. We are here to protect you and we will not leave you alone!

Alì: I feel good; I feel safer. Ifeel like I'm hugging both of you! (Happy Child)

In the following session, the patient stated that he had always felt a deep hatred for the abuser which diminished with the exercise. Afterwards, Alì reported of having been involved in numerous brawls from the ages of 20 to 28 because of his impulsiveness. Because of these fights he was detained by the police for some days for about seven times. Alì realized that thanks to therapy he had acquired greater self-control skills. Throughout the second year of therapy, Alì showed a progressive improvement in his relationships. The patient began to 
SCHEMA THERAPY FOR COMPLEX DISSOCIATIVE DISORDER

report daily life episodes in which he could better manage anger and shame by means of assertive strategies. Overall, Alì's social integration was proceeding positively. His knowledge of Italian was also improving. The patient reported a remarkable improvement in his dissociative and posttraumatic symptoms.

The limited reparenting process. According to ST, the therapeutic relationship conceptualized as limited reparenting - is a fundamental vehicle to establish corrective emotional experiences (Nordahl \& Nysæter, 2005; Young et al., 2003). Through limited reparenting, the therapist creates an active, caring, parent-like relationship with the patient, while respecting the boundaries of the therapeutic relationship. Although developing a limited reparenting relationship with a patient with CDD can be challenging, it is an essential component of the therapeutic process. Co-therapy with a male and female therapist increased the complexity of the therapeutic relationship. Following a situation in which Alì experienced unfairness that triggered his mistrust and abandonment schemas, an example of limited reparenting in co-therapy is provided here:

Ali: A few days ago, the director of my center went to my room when I was not there and found dirt because my roommates were never cleaning. I went to her to try to explain. I knocked on the door and she looked at me, she lowered her eyes and did not consider me. She told me: "Later, later, later!". I thought she did not want to talk to me. There was also a lawyer in her office. This lawyer never wanted to talk to me; I feel she does not want me. At that moment I was destroyed. I felt that there was no more space for me in that center. Ifelt that I was finished because before that moment I had given the director a little faith. I felt anger, anger! The heart was beating fast. Breathing became faster. My hands were shaking.

Dr. A.B.: I can imagine that you felt angry and mistreated, because you have been dismissed without the possibility of explaining. Did this episode remind you of similar moments in your childhood? 


\section{SCHEMA THERAPY FOR COMPLEX DISSOCIATIVE DISORDER}

Alì: (He thinks for a short moment) Yes! I felt the same feelings when my mother first and my stepmother later did not want me and threw me out. My stepmother sometimes convinced my father that I had to stay away from him. This was unfair, it was terrible!

Dr. A.B.: I understand that these have been very painful moments for you as every child has the right to be welcomed and treated fairly by their parents. That is what you missed in your childhood.

Alì: Yes, you are right! The lawyer was happy that the director had kicked me out like when my father scolded me and my stepmother was happy for it.

Dr. A.B.: I understand how you must have felt. Isn't it possible, however, that the director was just very busy at the time, perhaps even under stress, and she just wanted to tell you to come back later?

Ali: Yes, but she could at least have greeted me and made me say a few words instead of throwing me in that disdainful way. I felt like human trash!

Dr. F.V.C.: I understand that at that moment you were asking for attention and to be welcomed. We want you to know that we are close to you and we want to help you to overcome these difficult situations and these painful emotions. We are by your side and genuinely interested in you as a person.

The therapeutic relationship developed with different characteristics depending on the mode presented by the patient. Alì appeared initially distrustful, mainly showing the avoidant coping mode (i.e., the Detached Protector). After the first months of treatment, Alì seemed fragile and in need of care. The Abandoned/Abused Child and the Punitive Parent were the most frequently present modes during the sessions. As the therapy progressed, Alì showed a growing trust in the therapists, and he also showed a tendency to idealise them. In the second phase, the patient progressively developed the ability to open up with the therapists, overcoming the avoidance of traumatic memories. The therapy gradually brought out new 
SCHEMA THERAPY FOR COMPLEX DISSOCIATIVE DISORDER

painful episodes of childhood that the patient urgently needed to communicate. In this phase, the Angry Child mode tended to emerge more easily, but also the Healthy Adult was progressively present with greater stability.

\section{Third Phase of Psychotherapy (Integration and resocialization; eleven months approximately)}

This phase of the therapy was focused on consolidating therapeutic gains and in supporting Ali's progressive autonomy in his daily life. In order to encourage the autonomy of the patient towards the therapists, one of the two therapists (Dr. F.V.C.) began to progressively decrease her presence in the sessions. Over a period of about 10 months the sessions were reduced to one every two weeks. Throughout the third phase, Alì expanded progressively his social and professional network. Alì began to attend a carpentry internship and a cultural mediation course. He also did some job interviews. Relationship problems were less frequent in this phase. Most of the episodes concerned apparently minor situations (e.g., the queue at the dentist, the menu in the canteen, a reproach from the carpentry teacher) in which Alì felt unloved, alone and rejected. Such situations triggered the Angry Child's mode and emotions of helpless anger. Interventions such as role-playing and social skills training were used with the aim of promoting healthier relationships. Two-chair exercises focused on the dialogue between the Angry Child and the Healthy Adult were performed. The cognitive work was aimed at strengthening the Healthy Adult's perspective, always asking the following questions to the patient: "What would Alì Kebir say?" and "What would he do?". IR were performed on episodes of childhood domestic violence that emerged at this stage (e.g., the episode of Ali's brother beating his sister and their father wanting to kill them). At this stage, Alì reported a marked reduction of amnesia episodes in his daily life.

\section{Termination of psychotherapy}

Psychotherapy was interrupted in the third phase since Alì decided to move to 
SCHEMA THERAPY FOR COMPLEX DISSOCIATIVE DISORDER

northern Italy where he had contacts with compatriots who could guarantee him a stable job. He wrote a long thank you message to greet the whole MEDU team. He also gave the therapists a painting that depicted him as a 10-year-old boy who, wearing a MEDU t-shirt, coming out happy from a pond where he played with other children: "I felt as if, thanks to therapy, I was happy as a child" (Figure 1e). Thus, the psychotherapy stopped when the process of traumatic memories retrieving as well as the change and the integration of the modes were still occurring.

\section{Follow-up interviews (six months after the end of therapy)}

Six months after ending ST, the therapists invited Alì for some follow-up interviews. Alì immediately agreed saying that he was happy to be able to speak again with the therapists who had helped him so much. After spending a few months in northern Italy, unhappy with the working conditions, he moved to Germany where he sought asylum. There, he lived in a refugee reception center. During the online interviews, he talked about his difficulties after ending therapy. When he was in Germany, his mother died and he tested positive for Covid19. The patient described that difficult moment as follows: "I was desperate and jumped under a car. I did not get hurt but they took me to a psychiatric ward. I wanted to hurt myself a little and then come back alive. After this period of crisis, things are better now".

As requested by the therapists, Alì wrote the following evaluation in response to this question: how is it with your different sides (modes) at the moment? "Before answering this question, I would like to say something. Knowing how my personalities work gave me the motivation to understand the torment in which I lived and for which I had no explanation. This awareness has helped me a lot. To answer the question, I have noticed an overall improvement. Alì Kebir is now stronger and more present even if in the most difficult moments Alì the Abandoned Child still suffers. The positive changes due to therapy have been many and I'm not the only one to notice them, but also the people close to me. For 
SCHEMA THERAPY FOR COMPLEX DISSOCIATIVE DISORDER

example, I isolate myself much less from others.”.

\section{Quantitative Assessment of Psychotherapy Outcome}

As an overall consideration, it should be noted that the results of the measures administered to patients with CDD are often inconsistent, because these depend on which self-state participated in the assessment and on the fact that self-states may inhibit truthful responses (Van der Hart et al., 2006). In order to examine Alì's change from pre- to posttreatment and follow-up, we used the reliable change index (RCI; Jacobson \& Truax, 1991). The RCI provides a $z$-score, where higher scores correspond with improvement and the threshold for significant improvement (at $p<.05$ ) lies at a $z$-score $\geq 1.96$. To calculate the RCI, we used reliability coefficients and standard deviations from validation studies for YSQ-SF (Khater et al., 2011) and PCL-5 (Ibrahim et al, 2018). For the DES-II, we used the reliability coefficients and the standard deviations obtained in a sample of 10 Arabicspeaking asylum seekers who sought treatment at the Psyché Clinical Center for traumarelated psychological distress. A small study of reliability of the scale was carried out on the 10 asylum seekers. Cronbach's $\alpha$ coefficients calculated for the DES-II scale showed high alpha value $(\alpha=.87)$. Cronbach's $\alpha$ values for DES-II sub-scales (Taxon, Amnestic Dissociation, Depersonalization/Derealization, Absorption \& Imaginative Involvement) were $\alpha=.79, \alpha=.71, \alpha=.63$, and $\alpha=.54$, respectively. Effect sizes (Cohen's $d$ ) were calculated as the difference between pretreatment and posttreatment or follow-up means divided by the standard deviations for the YSQ-SF, PCL-5, and DES-II from normative samples (as mentioned above). Table 2 provides the mid- and/or posttreatment and follow-up scores on the YSQ-SF schema domains, PCL-5 total and subscale scores, DES-II total and subscale scores, the reliable change indices, and effect sizes.

Early maladaptive schemas (YSQ-SF). The scores on the YSQ-SF decreased significantly from pre- to posttreatment for all the EMS domains. From pretreatment to 
SCHEMA THERAPY FOR COMPLEX DISSOCIATIVE DISORDER

follow-up, the decrease in the score remained significant for two of the five EMS domains: Over-vigilance/Inhibition and Other-directedness.

Posttraumatic Stress Disorder (PCL-5). PCL-5 total score decreased significantly from pre- to posttreatment and follow-up to the point that at posttreatment and follow-up, Alì no longer met the DSM-5 criteria for the diagnosis of PTSD and the total scores (respectively 22 and 28) were below the PCL-5 indicative cut-off (33) for PTSD (Weathers et al., 2013).

Dissociative symptoms (DES-II). The total score of the DES-II and each of its subscales decreased significantly from pre- to posttreatment. At posttreatment, the total score (26.8) was below the indicative cut-off (30) for a DD (Carlson, Putnam, Ross, Torem, Coons, Dill et al., 1993). The decrease in score also remained significant at follow-up. Notably, the total and each subscale scores recorded a further decrease at follow-up with the exception of the Absorption \& Imaginative Involvement subscale.

\section{Process Measures Ratings}

The Helping Alliance (HAQ-II). HAQ-II collects data from both the therapist and the patient to measure the strength of the bond between them (Luborky et al., 1996). All the patient and therapists HAQ-II scores are displayed in Table 5. The suggested cut-off point for good versus poor alliance was 4.57 mean score (Luborsky et al., 1996). While at the beginning of psychotherapy only one score out of four was above the cut-off (Therapist II versus Patient), in the second and third year all four scores were above the cutoff point indicating good therapeutic alliance between the patient and the therapists.

\section{Discussion}

This single case study is the first to describe a ST treatment for a CDD patient, with comorbid BPD and PTSD, in a cross-cultural setting. ST was used within a phase-oriented approach. Although it was interrupted in the third phase when the improvements were still ongoing, the therapy showed a partial effectiveness. 


\section{SCHEMA THERAPY FOR COMPLEX DISSOCIATIVE DISORDER}

This case study is consistent with ST conceptualization of dissociation, in which CDD's different self-states can be conceptualized as extreme forms of non-integrated dysfunctional modes. A schema mode can be defined according to the position it occupies along a dissociation spectrum from an extreme in which an individual is able to activate/express more than one mode at the same time (i.e., normal mood changes) to the opposite extreme in which an individual uses a mode, without having, at that moment, the awareness of the others (i.e., DID). Accordingly, the substantial difference between DID identities and BPD modes would be the intensity and severity of the modes' dissociation. Taking into consideration this spectrum, Alì's complex dissociative disorder (i.e., OSDD, type 1) can be placed between BPD and DID, the severity and intensity of its modes' dissociation being higher than the former and lower than the latter. Recent studies have also shown that some typical modes of BPD present in Alì (e.g., the Angry Child, the Abandoned

Child, the Detached Protector), would be able to significantly predict dissociative experiences (Johnston et al., 2009, Barazandeh, Kissane, Saeedi \& Gordon, 2018). Furthermore, Johnston et al. (2009) showed how in the cases of BPD they studied it was not the childhood trauma per se that lead to the dissociative symptoms, but rather the dysfunctional modes originating from the childhood trauma. From a clinical and therapeutic point of view, the work of Johnston et al. (2009) confirmed the importance of identifying and integrating the modes originating from the EMS (in particular the modes Angry Child and Abandoned Child) as well as strengthening the Healthy Adult in these type of patients. Accordingly, Ali's pervasive dissociative experiences would stem in dysfunctional modes (i.e., the different "personalities" recognized by Alì) originated in turn from neglect and childhood trauma. Moreover, complex traumatic events occurred in Ali's adulthood would have acted as additional elements favouring the division of the parts of the personality (i.e., not-integrated dysfunctional schema modes) and consequently the dissociative symptoms. 
SCHEMA THERAPY FOR COMPLEX DISSOCIATIVE DISORDER

In accordance with other authors (Brand et al., 2019), we believe that ST for CDD should be used within a phase-oriented approach, and even more when, as it often occurs, BPD and PTSD occur comorbidly. In the case of Alì, creating a solid therapeutic alliance with both therapists and improving patient affect regulation and coping skills were essential stabilization phase steps in order to apply the ST's mode approach as well as to face the elaboration of traumatic memories. Using a stabilization phase does not necessarily mean adopting an excessively long therapy or never reaching the stage of traumatic memories' elaboration as claimed by Huntjens and colleagues (2019). In the case of Alì, the stabilization phase lasted 17 sessions, just one more than the 16 sessions of education phase proposed in the Huntjens et al.'s ST protocol for DID. Furthermore, the findings of this study highlight the importance of completing the third treatment phase (i.e., integration) when CDD, BPD and PTSD occur comorbidly. In the case of Alì, the significant improvements in all the EMS domains as well as in the prominent dissociative and posttraumatic symptoms reached at the termination of therapy were not fully maintained at the six-months follow-up. While the patient maintained significant improvements in two EMS domains, and in dissociative and posttraumatic symptoms, the improvements of some of the EMS domains were not. In particular, the Disconnection/Rejection domain score returned almost to pretreatment level. We assumed that not having completed the integration phase may subsequently have favored the re-emergence of the more rooted EMS (i.e., Disconnection/Rejection). Moreover, this case study confirms that the treatment of complex posttraumatic and dissociative disorders is often marked by recurrent relapses for which it is necessary to return from an advanced phase to a previous therapeutic stage (e.g., from integration phase to elaboration of traumatic memories) so that the therapy, rather than a linear progression, resembles a spiral path (Chu, 1998).

Another relevant element of the current case study refers to co-therapy which presents 
SCHEMA THERAPY FOR COMPLEX DISSOCIATIVE DISORDER

noteworthy aspects regarding the limited reparenting. Indeed, in the course of Ali's therapy, a double limited reparenting developed in which the two therapists (a woman and a man) took the role of the patient's parental figures (see Figure 1b; “Alì Child”). This clinical case shows that in a ST co-therapy, the two reparenting dyad (i.e., patient - male therapist and patient female therapist) can act in a complementary and synergistic way allowing a solid therapeutic relationship, which is essential for all the three treatment phases of a CDD patient. In our case, the progressive and balanced growth of Ali's therapeutic alliance with both therapists is statistically highlighted by the HAQ-II administered in the first and third year of therapy: i.e. the scale scores of the patient versus the therapists and vice versa were similar to each other presenting a specular evolution.

Dealing with the emotions related to traumatic experiences and countering the adult abuser through experiential work (i.e., IR) was a fundamental step of the therapy. In consideration of the patient's vulnerability and to prevent dissociative reactions, the technique IR was introduced gradually and with particular caution. The safe place and the imagery for assessment exercises were performed in the sixth month of therapy after the stabilization phase. The first IR was made after one year of therapy, while the episode of child abuse was dealt with much later during the second year of therapy, after having previously addressed it at a cognitive level.

One of the most interesting aspects of our case study was related to the cross-cultural validity of ST. To our knowledge, this is the first case study where ST was applied to the treatment of a CDD in a non-Western patient. In this regard, it is relevant to note that the patient had explicitly and spontaneously remarked several times, both during the therapy and during the follow-up interviews, how well he recognized himself in the conceptualization of the case and in the approach of the modes (which he called "personalities"). Although the role of the interpreter was essential in assigning the closest words to describe the emotions 
SCHEMA THERAPY FOR COMPLEX DISSOCIATIVE DISORDER

felt by the patient, we believe that the understanding of the characteristics and functions of the different modes were the result of a genuine elaboration of the patient. Of note, through his paintings, the patient was also able to visually represent some of his modes. Indeed, drawing and painting were important tools throughout the therapeutic process that facilitated the non-verbal communication of the modes, emotional states and traumatic experiences.

The findings of our study have several limitations. First, very few studies with small samples investigated the validity and reliability of the Arabic versions of the DES-II and YSQ-SF measures. The scores on these questionnaires must therefore be interpreted with caution. Indeed, the cross-cultural adaptation of a psychological self-administered questionnaire is a complex task requiring that, the items must not only be translated appropriately linguistically, but also adapted culturally to maintain the content validity of the instrument at a conceptual level across different cultures (Beaton, Bombardier, Guillemin \& Ferraz, 2000). Second, as there were no measures for the therapeutic alliance available in Arabic, we used the Italian version of the HAq-II whose items were translated into Arabic by the interpreter for the patient when filling in the questionnaire. This process could have resulted in some minor differences in meaning and/or understanding during the translation. Furthermore, in our study, follow-up interviews took place six months after the termination of therapy. A longer-term follow-up would be necessary to confirm the stability of the changes achieved with the therapy.

\section{Conclusion}

This case study shows that ST within a phase-oriented approach may be an effective treatment for CDD. Our study also suggests cross-cultural validity of ST and, particularly, of modes construct. Despite the evidence-based design, the features of this study (i.e., single case study) limit the generalizability of the results. This study therefore serves as a prime investigation of the effectiveness of ST approach to CDD in a cross-cultural setting. More 


\section{SCHEMA THERAPY FOR COMPLEX DISSOCIATIVE DISORDER}

research based on lager samples is needed to confirm these assumptions. Of note, a caseseries study to test the hypothesis that ST is an effective treatment for DID is currently in progress (Huntjens et al., 2019).

\section{References}

Al-Eithan, M., Al Juban, H., \& Robert, A. A. (2013). Dissociative experiences and their relationship to mood problems among Arab mothers of disabled children. The Pan African Medical Journal, 15, 21. https://doi.org/10.11604/pamj.2013.15.21.2229

American Psychiatric Association (2013). Diagnostic and statistical manual of mental disorders. 5th edition. Arlington, VA: American Psychiatric Publishing.

Barazandeh, H., Kissane, D. W., Saeedi, N., \& Gordon, M. (2018). Schema modes and dissociation in borderline personality disorder/traits in adolescents or young adults. Psychiatry Research, 261, 1-6. https://doi.org/10.1016/j.psychres.2017.12.023

Beaton, D. E., Bombardier, C., Guillemin, F., \& Ferraz, M. B. (2000). Guidelines for the process of cross-cultural adaptation of self-report measures. Spine, 25(24), 31863191. https://doi.org/10.1097/00007632-200012150-00014

Brand, B. L., Classen, C. C., Lanius, R., Loewenstein, R. J., McNary, S. W., Pain, C., \& Putnam, F. W. (2009). A naturalistic study of dissociative identity disorder and dissociative disorder not otherwise specified patients treated by community clinicians. Psychological Trauma Theory Research Practice and Policy, 1(2):153-171

Brand, B. L., Loewenstein, R. J., Schielke, H. J., van der Hart, O., Nijenhuis, E., Schlumpf, ...\& Reinders, A. (2019). Cautions and concerns about Huntjens et al.'s Schema Therapy for Dissociative Identity Disorder. European Journal of Psychotraumatology, 10(1), 1631698. https://doi.org/10.1080/20008198.2019.1631698 
SCHEMA THERAPY FOR COMPLEX DISSOCIATIVE DISORDER

Carlson, E. B., Putnam, F. W., Ross, C. A., Torem, M., Coons, P., Dill, D. L., ...\& Braun, B. G. (1993). Validity of the Dissociative Experiences Scale in screening for multiple personality disorder: a multicenter study. The American Journal of Psychiatry, 150(7), 1030-1036. https://doi.org/10.1176/ajp.150.7.1030

Carlson, E. B., \& Putnam, F. W. (1993). An update on the Dissociative Experiences Scale. Dissociation, 6, 16-27.

Chu, J.A. (1998). Rebuilding shattered lives: the responsible treatment of complex posttraumatic and dissociative disorders. New York: Wiley.

Cockram, D. M., Drummond, P. D., \& Lee, C. W. (2010). Role and treatment of early maladaptive schemas in Vietnam veterans with PTSD. Clinical Psychology \& Psychotherapy, 17, 165-182. doi:10.1002/cpp.690

Dalenberg, C. J., Brand, B. L., Gleaves, D. H., Dorahy, M. J., Loewenstein, R. J., Cardeña, ...\& Spiegel, D. (2012). Evaluation of the evidence for the trauma and fantasy models of dissociation. Psychological Bulletin, 138(3), 550-588.

\section{https://doi.org/10.1037/a0027447}

Farrell, J. M., Shaw, I. A., \& Webber, M. A. (2009). A schema-focused approach to group psychotherapy for outpatients with borderline personality disorder: a randomized controlled trial. Journal of Behavior Therapy and Experimental Psychiatry, 40(2), 317-328. https://doi.org/10.1016/j.jbtep.2009.01.002

Figley, C. R. (1995). Compassion fatigue as secondary traumatic stress disorder: An overview. In C. R. Figley (Ed.), Compassion fatigue: Coping with secondary traumatic stress disorder in those who treat the traumatized (pp. 1-20). New York: Brunner/Mazel.

First, M. B., Williams, J. W. B., Karg, R. S., \& Spitzer, R. L. (2016a). Structured Clinical Interview for DSM-5® Disorders--Clinician Version (SCID-5-CV). Washington: 
SCHEMA THERAPY FOR COMPLEX DISSOCIATIVE DISORDER

American Psychiatric Association Publishing.

First M. B., Williams, J. W. B., Karg R. S., \& Spitzer R. L. (2016b). Structured Clinical Interview for DSM-5® Personality Disorders (SCID-5-PD). Washington: American Psychiatric Association Publishing.

Giesen-Bloo, J., van Dyck, R., Spinhoven, P., van Tilburg, W., Dirksen, C., van Asselt, T., ...\& Arntz, A. (2006). Outpatient psychotherapy for borderline personality disorder: randomized trial of schema-focused therapy vs transference-focused psychotherapy. Archives of General Psychiatry, 63(6), 649-658. https://doi.org/10.1001/archpsyc.63.6.649

Herman, J. L., Perry, J. C., \& van der Kolk, B. A. (1989). Childhood trauma in borderline personality disorder. The American Journal of Psychiatry, 146(4):490-495.

Herman, J. L. (1997). Trauma and Recovery: The Aftermath of Violence-from Domestic Abuse to Political Terror. New York: Basic Books.

Huntjens, R., Rijkeboer, M. M., \& Arntz, A. (2019). Schema therapy for Dissociative Identity Disorder (DID): rationale and study protocol. European Journal of Psychotraumatology, 10(1), 1571377. https://doi.org/10.1080/20008198.2019.1571377

Ibrahim, H., Ertl, V., Catani, C., Ismail, A. A., \& Neuner, F. (2018). The validity of Posttraumatic Stress Disorder Checklist for DSM-5 (PCL-5) as screening instrument with Kurdish and Arab displaced populations living in the Kurdistan region of Iraq. BMC psychiatry, 18(1), 259. https://doi.org/10.1186/s12888-018-1839-z

International Society for the Study of Trauma and Dissociation (2011). Guidelines for treating dissociative identity disorder in adults, third revision: summary version. Journal of Trauma and Dissociation. ;12(2):188-212. doi:

10.1080/15299732.2011.537248. PMID: 21391104. 


\section{SCHEMA THERAPY FOR COMPLEX DISSOCIATIVE DISORDER}

Janet, P. (1907). The major symptoms of hysteria. New York, NY: Macmillan.

Johnston, C., Dorahy, M. J., Courtney, D., Bayles, T., \& O'Kane, M. (2009). Dysfunctional schema modes, childhood trauma and dissociation in borderline personality disorder. Journal of Behavior Therapy and Experimental Psychiatry, 40(2), 248-255. https://doi.org/10.1016/j.jbtep.2008.12.002

Khater, M. EL., Gilany, H., EL-Belsha, M., \& Abdel- Moneim, A. (2011). Reliability of the Arabic version of the Young Schema Questionnaire short-form among orphanage residents, Middle East Journal of Psychiatry and Alzheimers, 2(1): 3- 7.

Krüger, C. (2020). Culture, trauma and dissociation: A broadening perspective for our field. Journal of Trauma \& Dissociation, 21(1), 1-13. https://doi.org/10.1080/15299732.2020.1675134

Jacobson, N. S., \& Truax, P. (1991). Clinical significance: a statistical approach to defining meaningful change in psychotherapy research. Journal of Consulting and Clinical Psychology, 59(1), 12-19. https://doi.org/10.1037//0022-006x.59.1.12

Liotti, G. (1992). Disorganized-disoriented attachment in the etiology of the dissociative disorders. Dissociation: Progress in the Dissociative Disorders, 5(4):196-204.

Lobbestael, J., van Vreeswijk, M., \& Arntz, A. (2007). Shedding light on schema modes: A clarification of the mode concept and its current research status. Netherlands Journal of Psychology, 63(3), 76-85.

Luborsky, L., Barber, J. P., Siqueland, L., Johnson, S., Najavits, L. M., Frank, A., \& Daley, D. (1996). The Revised Helping Alliance Questionnaire (HAq-II) : Psychometric Properties. The Journal of Psychotherapy Practice and Research, 5(3), 260-27

Myrick, A. C., Webermann, A. R., Langeland, W., Putnam, F. W., \& Brand, B. L. (2017). Treatment of dissociative disorders and reported changes in inpatient and outpatient cost estimates. European Journal of Psychotraumatology, 8(1), 1375829. 


\section{SCHEMA THERAPY FOR COMPLEX DISSOCIATIVE DISORDER}

https://doi.org/10.1080/20008198.2017.1375829

Nordahl, H. M., \& Nysæter, T. E. (2005). Schema therapy for patients with borderline personality disorder: A single case series. Journal of Behavior Therapy and Experimental Psychiatry, 36(3), 254-264.

Putnam, K.T., Harris, W.W., \& Putnam, F.W. (2013). Synergistic childhood adversities and complex adult psychopathology. Journal of Traumatic Stress, 26(4):435-42. doi: 10.1002/jts.21833. Epub 2013 Jul 25. PMID: 23893545.

Ross, C.A. (2007). Borderline personality disorder and dissociation. Journal of Trauma \& Dissociation, 8(1):71-80. doi:10.1300/J229v08n01_05.

Ross, C. A. (1989). Multiple personality disorder: Diagnosis, clinical features, and treatment. New York, NY: Wiley

Russell, A., \& Russell, L. (1979). "The Uses and Abuses of Co-Therapy". Journal of Marital and Family Therapy. 5(1): 39-46. doi:10.1111/j.17520606.1979.tb00552.x. ISSN 1752-0606.

Sar, V., Akyuz, G., Kugu, N., Ozturk, E., \& Ertem-Vehid, H. (2006). Axis I dissociative disorder comorbidity in borderline personality disorder and reports of childhood trauma. The Journal of Clinical Psychiatry, 67(10), 1583-1590. https://doi.org/10.4088/jcp.v67n1014

Şar, V. (2017). Parallel-distinct structures of internal world and external reality: Disavowing and re-claiming the self-identity in the aftermath of trauma-generated dissociation. Frontiers in Psychology, 8. doi:10.3389/ fpsyg.2017.00216

Sar, V. (2011). Epidemiology of Dissociative Disorders: An overview. Epidemiology Research International. doi:10.1155/2011/404538

Schauer, M., Neuner, F., \& Elbert, T. (2011). Narrative Exposure Therapy: A short Term Treatment for Traumatic Stress Disorders (2nd edition). Cambridge, MA: Hogrefe 


\section{SCHEMA THERAPY FOR COMPLEX DISSOCIATIVE DISORDER}

Publishing.

Schore, A. N. (2009). Attachment trauma and the developing right brain: Origins of pathological dissociation. In P. F. Dell PF \& J. A. O'Neil (Eds.) Dissociation and the dissociative disorders: DSM-V and beyond (pp. 107-141) New York, NY US: Routledge/Taylor \& Francis Group.

Sexton, L. (1999). Vicarious traumatisation of counsellors and effects on their workplaces. British Journal of Guidance and Counselling, 27, 393-403.

Simeon, D., \& Loewenstein, R.J. (2009). Dissociative Disorders. In B. J. Sadock, V. A. Sadock, \& P. Ruiz (Eds.) Comprehensive Textbook of Psychiatry, Volume 1. 9th edition (pp. 1965-2026) Philadelphia, PA: Wolters Kluwer/Lippinoctt Williams \& Wilkens.

Van der Hart, O., Nijenhuis, E. R. S., \& Steele, K. (2006). The haunted self: Structural dissociation and the treatment of chronic traumatization. New York, NY: Norton.

Weathers, F., Litz, B., Keane, T., Palmieri, T., Marx, B.P., \& Schnurr, P. (2013). The PTSD Checklist for DSM-5 (PCL-5). Scale available from the National Center for PTSD at www.ptsd.va.gov.

Young, J. E. (1994). Cognitive Therapy for Personality Disorders: A Schema focused Approach. Professional Resource Exchange, Sarasota, FL.

Young, J. E., \& Fosse, G. (2005). Schema Therapy Rating Scale. New York: Cognitive Therapy Center of New York. doi:10.1007/978-90-313-7121-1

Young, J. E., Klosko, J. S., \& Weishaar, M. E. (2003). Schema therapy: A practitioner's guide. London: Guilford Press.

Zittel Conklin, C., \& Westen, D. (2005). Borderline personality disorder in clinical practice. The American Journal of Psychiatry, 162(5), 867-875. https://doi.org/10.1176/appi.ajp.162.5.867 
Table 1

List of Measures Used in the Case Study, When Administered, and by Whom

\begin{tabular}{|c|c|c|c|c|}
\hline Topic & Measures & Description & Time in treatment & Rated by \\
\hline $\begin{array}{l}\text { Dissociative } \\
\text { symptoms }\end{array}$ & $\begin{array}{l}\text { Dissociative } \\
\text { Experiences Scale-II } \\
\text { (DES-II ; Ibrahim et al., } \\
2018)\end{array}$ & $\begin{array}{l}\text { The DES-II is a } 28 \text {-item self- } \\
\text { report measure that assesses } \\
\text { dissociative symptoms. }\end{array}$ & $\begin{array}{l}\text { Pre-, mid-, } \\
\text { posttreatment and follw- } \\
\text { up }\end{array}$ & $\begin{array}{l}\text { Self-report } \\
\text { administered with an } \\
\text { independent interpreter support }\end{array}$ \\
\hline $\begin{array}{l}\text { Early } \\
\text { maladaptive } \\
\text { schemas }\end{array}$ & $\begin{array}{l}\text { Young Schema } \\
\text { Questionnaire Short } \\
\text { Form } \\
\text { (YSQ-SF; Khater at al., } \\
2011 \text { ) }\end{array}$ & $\begin{array}{l}\text { The YSQ-SF is a self-report } \\
\text { assessment instrument of } \\
75 \text { items, to assess the } 15 \text { EMS }\end{array}$ & $\begin{array}{l}\text { Pre-, mid-, posttreatment, } \\
\text { and follow-up }\end{array}$ & $\begin{array}{l}\text { Self-report } \\
\text { administered with an } \\
\text { independent interpreter support }\end{array}$ \\
\hline $\begin{array}{l}\text { Posttraumatic } \\
\text { Stress Disorder }\end{array}$ & $\begin{array}{lr}\text { PTSD } & \text { Checklist for } \\
\text { DSM-5 } & \text { (PCL-5; } \\
\text { Ibrahim et al., 2018) }\end{array}$ & $\begin{array}{l}\text { The PCL-5 is a } 20 \text {-item self- } \\
\text { report measure that assesses the } \\
20 \text { DSM- } 5 \text { symptoms of PTSD. }\end{array}$ & $\begin{array}{l}\text { Pre-, mid-, posttreatment, } \\
\text { and follow-up }\end{array}$ & $\begin{array}{l}\text { Self-report } \\
\text { administered with an } \\
\text { independent interpreter support }\end{array}$ \\
\hline $\begin{array}{l}\text { Therapeutic } \\
\text { alliance }\end{array}$ & $\begin{array}{ll}\text { Helping } & \text { Alliance } \\
\text { Questionnaire } & \text { (HAq-II; } \\
\text { Luborsky at al, } & 1996)\end{array}$ & $\begin{array}{l}\text { The HAq-II is a } 19 \text { item self- } \\
\text { report questionnaire that } \\
\text { measures the strength of the } \\
\text { client therapist alliance }\end{array}$ & $\begin{array}{l}\text { Pre-, mid-, and } \\
\text { posttreatment }\end{array}$ & $\begin{array}{l}\text { Self-report administered with an } \\
\text { independent interpreter support }\end{array}$ \\
\hline $\begin{array}{l}\text { Therapy } \\
\text { adherence }\end{array}$ & $\begin{array}{l}\text { Schema Therapy Rating } \\
\text { Scale (STRS; Young \& } \\
\text { Fosse, 2005) }\end{array}$ & $\begin{array}{l}\text { The STRS measures the } \\
\text { psychotherapist } \\
\text { competency in using ST. }\end{array}$ & $\begin{array}{l}\text { Two audiotaped sessions } \\
\text { during the second year of } \\
\text { psychotherapy }\end{array}$ & $\begin{array}{l}\text { An independent rater, } \\
\text { a certified ST } \\
\text { therapist }\end{array}$ \\
\hline
\end{tabular}


SCHEMA THERAPY FOR COMPLEX DISSOCIATIVE DISORDER

Note. Pretreatment = at the start of treatment (first phase); Midtreatment =beginning of second year of treatment (second phase); Posttreatment

=beginning of third year of treatment, except for the YSQ-SF, which was completed after 2-year and 4-months of treatment (third phase);

Follow-up $=6$ months after ending treatment.

Table 2

Scores on the YSQ-SF Schema Domains, PCL-5 and DES-II Scores, Reliable Change Indices, and Effect Sizes for Pretreatment to Posttreatment and Follow-Up

\begin{tabular}{|c|c|c|c|c|c|c|c|c|}
\hline Scales & Pretreatment & Midtreatment & Posttreatment & RCI & ES & Follow-up & $\mathrm{RCI}$ & $\mathrm{ES}$ \\
\hline \multicolumn{9}{|l|}{ YSQ-SF Schema } \\
\hline Domains & & & & & & & & \\
\hline $\begin{array}{l}\text { Disconnection/ } \\
\text { rejection }\end{array}$ & 3.6 & 2.0 & 0.2 & $3.79 *$ & 2.68 & 3.4 & 0.22 & 0.16 \\
\hline $\begin{array}{l}\text { Impaired autonomy/ } \\
\text { performance }\end{array}$ & 2.0 & 0.2 & 0.2 & $2.68 *$ & 2.34 & 1.2 & 1.19 & 1.04 \\
\hline Impaired limits & 3.5 & 1.5 & 1.5 & $1.98 *$ & 1.68 & 3.0 & 0.50 & 0.42 \\
\hline Other-directedness & 4.5 & 1.5 & 2.0 & $3.64 *$ & 3.00 & 2.0 & $3.64 *$ & 3.00 \\
\hline $\begin{array}{l}\text { Over- } \\
\text { vigilance/inhibition }\end{array}$ & 3.5 & 2.5 & 2.0 & $1.97 *$ & 1.74 & 1.5 & $2.63 *$ & 2.32 \\
\hline PCL-5 total & 42 & 23 & 22 & $3.62 *$ & 1.92 & 28 & $2.53 *$ & 1.34 \\
\hline Intrusion symptoms & 8 & 1 & 2 & $2.79 *$ & 1.94 & 3 & $2.33 *$ & 1.61 \\
\hline Avoidance & 5 & 1 & 1 & $3.52 *$ & 1.72 & 4 & 0.88 & 0.43 \\
\hline
\end{tabular}




\begin{tabular}{|c|c|c|c|c|c|c|c|c|}
\hline $\begin{array}{l}\text { Negative alterations } \\
\text { in cognition and } \\
\text { moods }\end{array}$ & 11 & 12 & 9 & 0.52 & 0.38 & 10 & 0.26 & 0.19 \\
\hline $\begin{array}{l}\text { Alterations in } \\
\text { Arousal }\end{array}$ & 18 & 9 & 10 & $2.28 *$ & 1.74 & 11 & $1.99 *$ & 1.52 \\
\hline DES-II total & 63.0 & 32.5 & 26.8 & $5.56 *$ & 2.84 & 18.2 & $6.82 *$ & 3.51 \\
\hline Taxon & 70.0 & 35.0 & 12.5 & $3.14 *$ & 2.03 & 10.0 & $3.27 *$ & 2.12 \\
\hline $\begin{array}{l}\text { Depersonalization/ } \\
\text { Derealization }\end{array}$ & 53.3 & 18.3 & 10.0 & $1.99 *$ & 1.71 & 3.3 & $2.30 *$ & 1.98 \\
\hline $\begin{array}{l}\text { Amnestic } \\
\text { Dissociation }\end{array}$ & 65 & 20 & 28.7 & $2.25 *$ & 1.71 & 5.0 & $3.71 *$ & 2.83 \\
\hline $\begin{array}{l}\text { Absorption } \\
\text { Imaginative } \\
\text { Involvement }\end{array}$ & 66.7 & 43.3 & 20.0 & $2.80 *$ & 2.69 & 36.7 & 1.80 & 1.73 \\
\hline
\end{tabular}

Note. RCI scores for the schema domains, PCL-5 and DES-II have been reversed to correspond with positive treatment progress; higher scores on the PCL-5 and DES-II mean respectively more PTSD and dissociative symptoms, and higher scores on schema domains mean more maladaptive schemas. RCI = Reliable Change Index; ES = Effect size; PCL-5 = PTSD Checklist for DSM-5; DES-II = Dissociative Experiences Scale-II.

$* p=.05$. 
SCHEMA THERAPY FOR COMPLEX DISSOCIATIVE DISORDER

Table 3

Helping Alliance Questionnaire Mean Scores (and SD) During the Course of Psychotherapy

\begin{tabular}{|c|c|c|c|}
\hline \multirow[b]{2}{*}{ HAQ-II scores } & \multicolumn{3}{|c|}{ Time during Psychotherapy } \\
\hline & First year & Second year & Third year \\
\hline \multicolumn{4}{|l|}{ Patient } \\
\hline Patient versus & $2.73(1.24)$ & $5.18(.78)$ & $5.31(.82)$ \\
\hline Therapist A.B. & & & \\
\hline Patient versus & $3.00(1.33)$ & $5.15(.67)$ & $5.26(.73)$ \\
\hline Therapist F.V.C. & & & \\
\hline \multicolumn{4}{|l|}{ Therapists } \\
\hline $\begin{array}{l}\text { Therapist A.B. versus } \\
\text { Patient }\end{array}$ & $4.05(.52)$ & $5.15(.61)$ & $5.21(.54)$ \\
\hline $\begin{array}{ll}\text { Therapist } & \text { F.V.C. } \\
\text { versus Patient } & \end{array}$ & $4.68(.89)$ & $5.22(.63)$ & $5.31(.67)$ \\
\hline
\end{tabular}

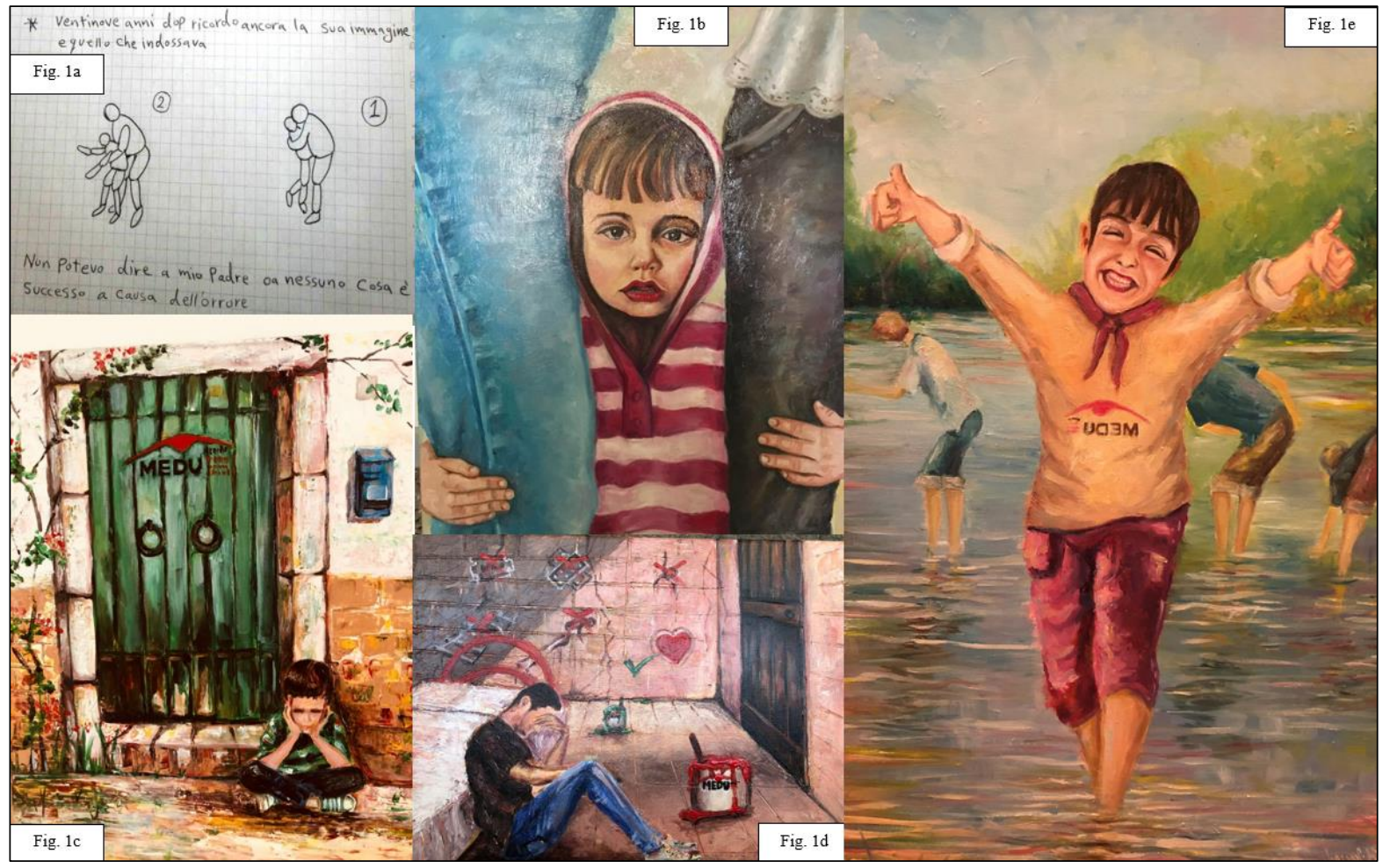

Figure 1. Drawings and paintings made by Alì relating to therapy: 1a) Re-enactment of the sexual abuse at the age of 10;1b) Alì Child with the therapists; 1c) Alì Abandoned Child; 1d) Alì the Solitary 


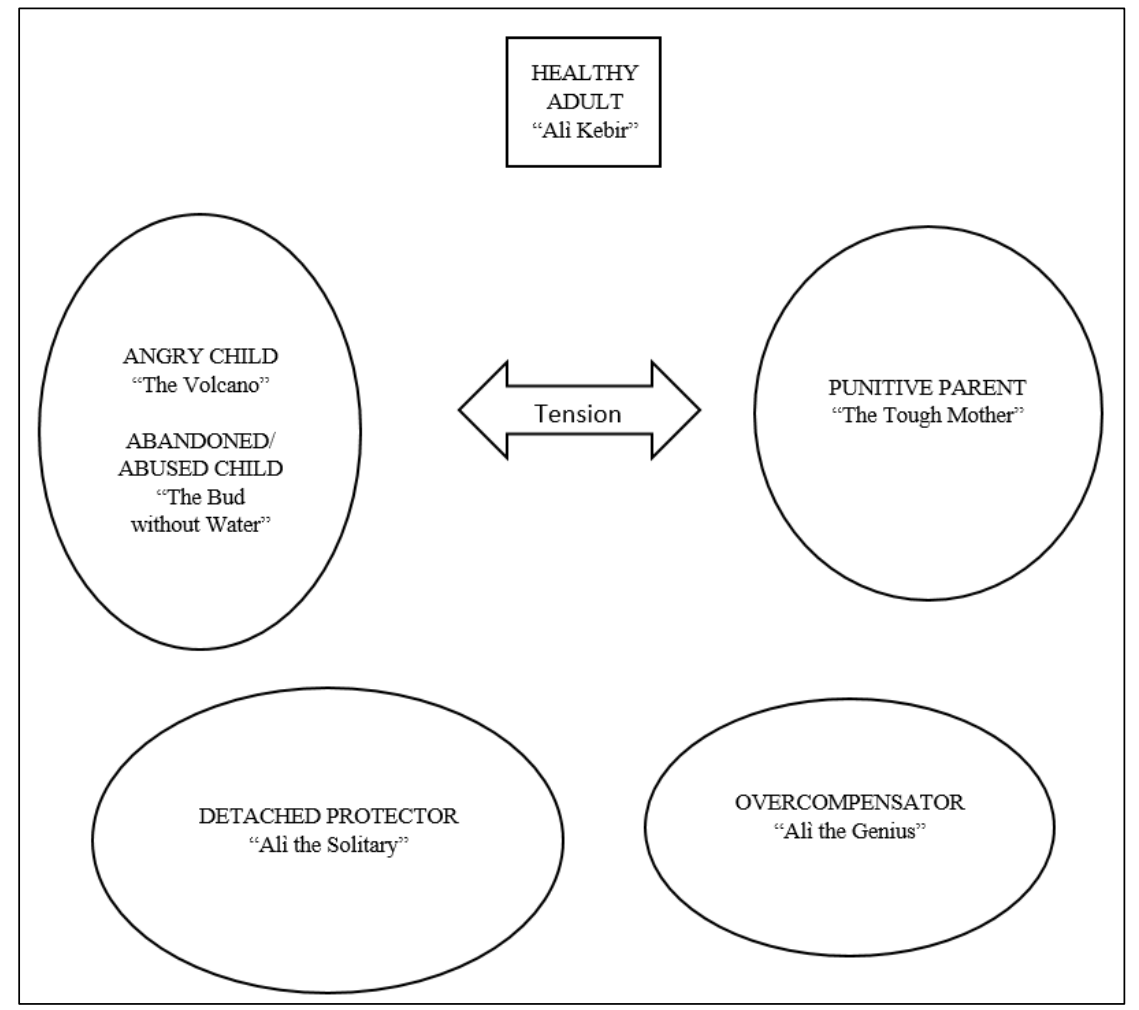

Figure 2. Schema Mode Model used in Alì's therapy. 